\title{
Settings for Pediatric Palliative Care in the United States
}

\author{
Ann Armstrong-Dailey Jane Koppelman \\ Children's Hospice International, Alexandria, Va., USA
}

Of the 55,000 children and youth who die annually in the United States, one third of them die from life-threatening conditions [1]. In any given year, about 1.3 million children suffer from serious illnesses and could benefit from hospice and palliative care services [2]. Since most children with life-threatening illnesses receive aggressive care until death, the majority of children die in institutions, hospitals, long-term care facilities or rehabilitation centers.

Less than $1 \%$ of children who need hospice and palliative care services receive any, according to Children's Hospice International (CHI). While this statistic is glaring, it has taken a while for US policymakers to become aware of the deficiencies in pediatric palliative care. In fact, about a decade after a comprehensive national study found gross inadequacies in the way that adults die in America - in terms of pain and symptom control, access to hospice care, and poor provider communication about treatment options for terminal patients [3] - the even grimmer landscape for pediatric palliative care finally came to public light in 2003 through an Institute of Medicine report entitled When Children Die. These government report's findings were condemning. It noted that children fail to receive competent, compassionate care that meets their physical, emotional, and spiritual needs, and that current methods of organizing and financing palliative, end-of-life, and bereavement care in the US health care system complicate the provision and coordination of services for children [4].

Put succinctly, instances of pediatric palliative care whether at home, in hospitals, or inpatient hospices are quite rare in the United States, a circumstance that $\mathrm{CHI}$ is seeking to change. This article will describe in more detail the barriers to expanding pediatric palliative (c) 2007 S. Karger AG, Basel

1011-7571/07/0167-0042\$23.50/0

Fax +4161306 1234

E-Mail karger@karger.ch

www.karger.com
Accessible online at:

www.karger.com/mpp care, and a model of care now being implemented in a number of states, with federal government support, that seeks to provide pediatric palliative care in a variety of settings.

\section{Current System}

The way that pediatric palliative care is paid for and organized in the USA is based on the hospice benefit that was designed for the federal Medicare program in 1983. It is an adult model of care based on the disease trajectory of cancer. Patients can receive a range of palliative services if they are diagnosed to be within 6 months of death, and only if they agree to forego any curative care (a decision designed to curb costs). Services come in the form of home nursing care, counseling, spiritual care, pain and symptom management, and bereavement care for surviving family members. While inpatient hospice care is available, most hospice care provided under Medicare is homebased. Nearly all private insurance plans have adopted Medicare's hospice benefit, as did Medicaid (the government's program for low-income disabled people) in 1993.

This adult model of hospice care fails children in a number of ways. First, parents identify the point of diagnosis as the most devastating time of the illness; family members are emotionally and spiritually paralyzed and find it difficult attending to the necessities of day-to-day living. Siblings often act out as most of their parents' attention is given to the sick child. Parents also feel overwhelmed with how to find and coordinate so many of the services their child will need. Yet both public and private insurers do not offer case management or counseling for families at the point of diagnosis. Moreover, parents and 
pediatricians are not prepared to make an either/or choice between treatments aimed at achieving comfort and treatments aimed at curing the disease. Parents say that choosing the hospice benefit means giving up on their child; pediatricians also do not want to turn over control of their patient to the care of others.

In addition, while cancer has a fairly predictable trajectory, many childhood diseases do not, and physicians say they cannot predict when most of their pediatric patients are within 6 months of death. As a result, dying children rarely receive hospice services; those who do, receive them very late in their disease. Moreover, parents of children receiving hospice benefits rarely get respite care in amounts sufficient to help them replenish the energy they need to care for a seriously ill child.

\section{New Model of Care}

In 1997, CHI, with technical assistance from the Centers for Medicare and Medicaid Services, Congress, and health care leaders, developed the Program for All-Inclusive Care for Children and their Families ${ }^{\circledR}$ (PACC) to overcome barriers to care for children with life-threatening conditions. Unlike traditional hospice/palliative care models, a CHI PACC program provides a continuum of care for children and their families from the time of diagnosis, with hope for a cure, and through bereavement if a cure is not attained.

Through congressional funding, $\mathrm{CHI}$ and the Centers for Medicare and Medicaid Services, using federal Medicaid funding, are implementing this model in six regions - Colorado, Florida, Kentucky, New York, New England, Utah, and Virginia.

Under the PACC model, families of children with lifethreatening conditions will not be forced to choose between curative care and hospice/palliative care, but instead will be offered palliative care alongside disease treatment. The model also offers early and continual intervention and case management to prepare families and health care providers to support the seriously ill child. Services include counseling for children and families, emotional and spiritual support, respite care for parents, expressive therapies for the child using music and art, and bereavement support if cure is not attained.

While the PACC model provides an enhanced Medicaid benefit package, early studies from Colorado and New York suggest that it will actually save money. Savings will come in the form of reduced hospital stays and trips to the emergency room because care is better managed and parents are educated about what to expect with their child's disease. Savings from these two states are estimated to range between USD 12,000 and USD 20,000 per child per year [5; pers. commun. with B. Greffe, director of the CHI PACC Colorado project, on June 8, 2005].

One of the advantages of the PACC model is that it pays for care in any setting - at home, in the hospital or in an inpatient hospice facility. The location of care is determined by what the disease calls for and where the patient and family feels most comfortable receiving care not by insurance rules that arbitrarily restrict location of care to a particular setting.

In addition, the CHI PACC model is administratively flexible - it can be headquartered in a variety of institutions. For instance, the PACC program in Colorado will be administered by a children's hospital, meaning that they will be responsible for spearheading and executing a plan of care for each child. In Kentucky, it will be a community hospice. In Florida, it is the Medicaid agency.

The hope underpinning expansion of CHI PACC as a permanent reimbursable model in Medicaid and private insurance is based on the adage, 'If you build it, they will come.' Currently only 438 of the more than 3,000 hospices in the United States are equipped to serve children. Very few pediatricians are trained in palliative care. Respite care and expressive therapies are hard to find in some sections of the country. It is hoped that reimbursement for this model will encourage the needed expertise, and services, to grow.

References
1 Field MJ, Behrman RE: When Children Die: Improving Palliative and End-of-Life Care for Children and Their Families. Washington, Institute of Medicine, 2001.

2 Gay JC, Muldoon JH, Neff JM, Wing LJ: Profiling the health service needs of populations: descriptions and uses of the NACHRI Classification of Congenital and Chronic Health Conditions. Pediatr Ann 1997;26: 655-663.

3 SUPPORT Investigators: A controlled trial to improve care for seriously ill hospitalized patients. The study to understand prognoses and preferences for outcomes and risks of treatments (SUPPORT). JAMA 1995;274: 1591-1598.

4 Field MJ, Behrman RE: When Children Die: Improving Palliative and End-of-Life Care for Children and their Families. Washington, Institute of Medicine, 2003.

5 Fitch K, Pyenson B: Palliative Care for Children with Life-Limiting Illness: An Actuarial Evaluation of Costs for a New York State Medicaid Demonstration Project. New York, Milliman Inc, 2003. 